\title{
The scale of COVID-19 graphs affects understanding, attitudes, and policy preferences
}

\author{
Alessandro Romano $^{1}$ | Chiara Sotis $^{2}$ () | Goran Dominioni ${ }^{1}$ | Sebastián Guidi ${ }^{1}$
}

${ }^{1}$ Yale Law School, New Haven, Connecticut, USA

${ }^{2}$ London School of Economics and Political Science, London, UK

Correspondence

Chiara Sotis, London School of

Economics and Political Science,

London, UK.

Email: c.sotis@lse.ac.uk

\begin{abstract}
Mass media routinely present data on coronavirus disease 2019 (COVID-19) diffusion with graphs that use either a log scale or a linear scale. We show that the choice of the scale adopted on these graphs has important consequences on how people understand and react to the information conveyed. In particular, we find that when we show the number of COVID-19 related deaths on a logarithmic scale, people have a less accurate understanding of how the pandemic has developed, make less accurate predictions on its evolution, and have different policy preferences than when they are exposed to a linear scale. Consequently, merely changing the scale the data is presented on can alter public policy preferences and the level of worry about the pandemic, despite the fact that people are routinely exposed to COVID-19 related information. Providing the public with information in ways they understand better can help improving the response to COVID-19, thus, mass media and policymakers communicating to the general public should always describe the evolution of the pandemic using a graph on a linear scale, at least as a default option. Our results suggest that framing matters when communicating to the public.

K E Y W O R D S

COVID-19, framing, media, public understanding

J E L C L A S S I F I C A T I O N

D90, D91, I10, I12, I18
\end{abstract}

\section{1 | INTRODUCTION}

The coronavirus disease 2019 (COVID-19) pandemic is a formidable challenge. Absent a cure or a vaccine, it is crucial that people are adequately informed about the pandemic (Everett, Colombatto, Chituc, Brady, \& Crockett, 2020), so that they stand behind policies that aim to minimize the spread of the virus and adopt behaviors that can limit the risk of contagion (Bursztyn, Rao, Roth, \& Yanagizawa-Drott, 2020). However, research has shown the challenges of communicating scientific facts in a way that effectively conveys essential information to the general public (Pidgeon \&

This is an open access article under the terms of the Creative Commons Attribution License, which permits use, distribution and reproduction in any medium, provided the original work is properly cited.

(c) 2020 The Authors. Health Economics published by John Wiley \& Sons Ltd. 
Fischhoff, 2011). In this article, we highlight the importance of this problem by focusing on one of the most basic pieces of information relative to the pandemic: the number of deaths.

To provide information on the diffusion of the virus, mass media routinely publish graphs that depict the evolution in the number of COVID-19 related deaths in a given area. Many of these graphs present quantities on the Y-axis on either a linear scale (The Washington Post, 2020; Vox, 2020) or a logarithmic scale (Financial Times, 2020; The Guardian, 2020; New York Times, 2020). The New York Times, for instance, has explained that the logarithmic scale helps better visualize exponential growth (New York Times, 2020). This follows advice given by epidemiology journals (Gladen, 1983; Levine, Ahmad, \& Asa, 2010) and data visualization handbooks (Kosslyn, 2006). However, what might be true for conveying information among experts might not hold when issuing information to a broader audience. The principle that logarithmic scales are better suited for exponential growth does not hold true if readers do not, in fact, comprehend them.

We show that scale choice has important consequences on how people understand and react to the information conveyed. In particular, we find that when people are exposed to a logarithmic scale they have a less accurate understanding of how the pandemic unfolded until now, make less accurate predictions on its future, and have different attitudes and policy preferences than when they are exposed to a linear scale. Another study (Ryan \& Evers, 2020) carried out a week after ours, confirms our finding that the scale of the graph affects policy preferences and that people have problems understanding logarithms. Instead, a study with Canadian respondents finds that the scale of the graph has no impact on respondents (Sevi et al., 2020). ${ }^{1}$ Previous studies have already shown that even experts have problems understanding graphs that use the logarithmic scale (Heckler, Mikula, \& Rosenblatt, 2013; Menge et al., 2018). However, unlike most studies on graph comprehension we test understanding of graphs that represents real world highly salient data about which the public is likely to have ample background information and to care deeply. The obvious relevance of the data depicted in the graphs also allows us to test the impact of the scale in which the data is plotted on preferences about important policy issues. Since providing the public with clear information can help improving the response to COVID-19 (Van Bavel et al., 2020), mass media and policymakers should present data on the evolution of the pandemic using a graph on a linear scale, at least as a default option.

\section{$2 \mid$ EXPERIMENT}

We devised a double-blind experiment approved by the Yale IRB to test people's graph comprehension and its effects on attitudes and policy preferences. We recruited a sample of approximately $n=2000$ (after exclusion criteria, with no regression with less than 1825 observations) U.S. residents on Cloud Research. Half of them were randomly assigned to the Linear Group, in which they were shown the evolution of COVID-19 deaths in the U.S. on a linear scale. The other half were assigned to the Log Group, in which participants saw the same data, but plotted on a logarithmic scale. The graphs were taken from the popular website www.worldometers.info (see Figure 1). We asked respondents three sets of questions: (1) attitudes and policy preferences, (2) graph understanding, and (3) standard demographic questions. In the Appendix S1, we report the questions we asked and the order in which they were asked.

The analyses can be grouped into: (1) determinants of worry, (2) policy preferences, and (3) differences in understanding. In all three cases, our primary variable of interest is "linear," a binary taking value 1 whenever the participant was exposed to the linear scale graphs, and 0 otherwise.

We start by showing participants in the two groups the graph plotting the evolution of the total number of deaths on the scale to which they were randomly assigned. Then we ask respondents in the two groups to indicate how worried they are about the health crisis and the economic crisis caused by COVID-19 on a five points Likert scale from "not worried at all" to "extremely worried." Second, we ask respondents about their preferences on some policies that many States have adopted to mitigate the spread of COVID-19. In the first pair of policy questions we ask whether they support the policy of closing nonessential businesses (five points Likert scale from "strongly disagree" to "strongly agree"), and until which date they would keep these businesses closed. In the second pair of policy questions we ask participants how often they would use a mask if the government sent a supply (five points Likert scale from "never" to "always"). Moreover, we ask whether they would support a tax that finances the distribution of masks for everyone in their State (five points Likert scale from "strongly oppose" to "strongly support").

We then turn to test respondents' understanding of the graphs. To increase external validity and to avoid priming respondents, we ask attitudes and policy preferences before testing understanding. This allows us to obtain respondents' 

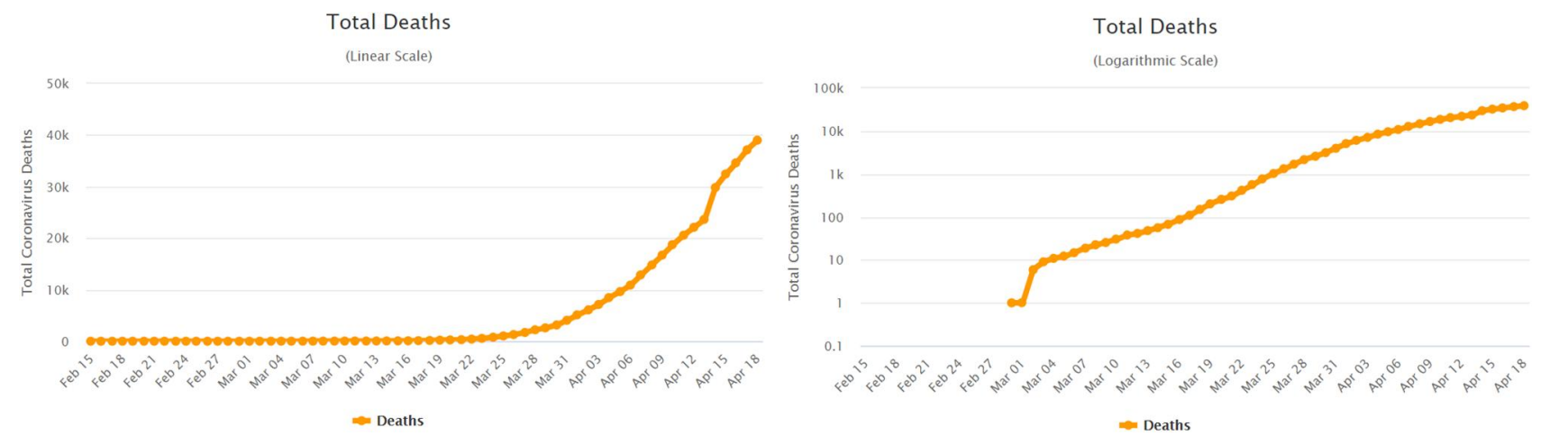

F I G U R E 1 COVID-19 related deaths in United States between February 15th and April 18th in a linear scale (left panel) and in a log scale (right panel). Source: www.worldometers.info

policy preferences before they are asked to think thoroughly about the graph and its meaning in a way that they would be unlikely to do when reading actual news.

We test understanding of graphs by asking three questions. First, we show them the COVID-19 graph on the scale that they had been assigned and ask them whether the number of deaths increased more between March 31st and April 6th or between April 6th and April 12th. Second, we show them a graph describing non-COVID-19 related data on the number of deaths from a hypothetical infection Z (taken from Okan, Galesic, \& Garcia-Retamero, 2016) and asked them a similar question. As for the first graph shown to participants, people in the Linear Group saw the data plotted on a linear scale, whereas respondents in the Log Group saw data plotted on a logarithmic one. The goal of this question was to test whether respondents' ability to answer correctly the first question depended on prior information on COVID-19, or on a correct understanding of the scale on which their graphs are plotted.

Third, we test whether respondents can make predictions based on the curve. In particular, we ask them to make a prediction on the total number of deaths on April 25th, one week after we launched the experiment.

Predicting the number of COVID-19 related deaths in a week is very difficult, but some predictions are more reasonable than others. We forecast the number of total deaths on April 25th using an ARIMA model, a standard forecasting method that has already been used to predict COVID-19 diffusion (Benvenuto, Giovanetti, Vassallo, Angeletti, \& Ciccozzi, 2020). We use an ARIMA $(0,2,1)$, as simulations show that it offers the best fit for the data, and forecast the number of cases and its $95 \%$ and $99 \%$ confidence intervals (CIs). On the 18th of April the number of deaths was 39,014. The 95\% CI forecasted using the ARIMA $(0,2,1)$ ranges from 49,203.15 to $62,559.27$, whereas the $99 \%$ CI ranges from $46,895.47$ to $64,685.95$. We remark that the actual number of deaths on the 25th of April was 54,256, while our ARIMA predicted 55,791 deaths predicted model. This is well within the CIs we consider.

We use these CIs to divide predictions in three groups. In the first group, we include the predictions that fall within the forecast 95\% CI ("accurate range"). We consider these predictions "accurate." In the second group, we include the predictions that fall within the $99 \%$ CI, but outside the 95\% CI ("unlikely range"). We refer to these predictions as "unlikely." Last, we consider the predictions that fall outside the 99\% CI ("unreasonable range") as "unreasonable."

Additionally, for each of the understanding questions we asked how confident respondents were about their answers. The level of confidence is important as it can shed some light on how much weight people will attach to the information represented in the graph.

We concluded by collecting standard demographic information on the respondents.

\section{$3 \quad$ RESULTS AND DISCUSSION}

Table 1 describes the characteristics of our sample. Figures 2 and 3 and Tables 2 and 3 show that people in the Linear Group understand the graphs better and make better predictions. The Log Group gives predictions that are higher and are on average unreasonable. Therefore, using linear scale graphs reduces the risk of confusing the public.

Moreover, the scale also impacts people level of worry for the health crisis (but not for the economic crisis) and their policy preferences. People in the Linear Group are more worried about the health crisis (see Table 4), and prefer that nonessential businesses remain closed for longer (Table 5). However, they support less strongly the idea of closing 
T A B L E 1 Frequency table for demographic variables: Number, percentage, and cumulative percentage of respondents for the following variables: Age, education, income, political orientation, gender, live in city with less than 50K people, and live in city with more than $500 \mathrm{~K}$ people

\begin{tabular}{|c|c|c|c|c|c|c|c|c|c|}
\hline & \multicolumn{9}{|c|}{ Graph shown } \\
\hline & \multicolumn{3}{|c|}{ Log scale } & \multicolumn{3}{|c|}{$\underline{\text { Linear scale }}$} & \multicolumn{3}{|c|}{ Total } \\
\hline & No. & $\begin{array}{l}\text { Percentage } \\
\%\end{array}$ & $\begin{array}{l}\text { Cum } \\
\%\end{array}$ & No. & $\begin{array}{l}\text { Percentage } \\
\%\end{array}$ & $\begin{array}{l}\text { Cum } \\
\%\end{array}$ & No. & $\begin{array}{l}\text { Percentage } \\
\%\end{array}$ & $\begin{array}{l}\text { Cum } \\
\%\end{array}$ \\
\hline \multicolumn{10}{|l|}{ Age } \\
\hline $18-25$ years old & 126 & 11.6 & 11.6 & 122 & 12.4 & 12.4 & 248 & 12.0 & 12.0 \\
\hline $36-45$ years old & 234 & 21.5 & 65.4 & 237 & 24.0 & 67.7 & 471 & 22.7 & 66.5 \\
\hline $46-55$ years old & 182 & 16.7 & 82.2 & 150 & 15.2 & 82.9 & 332 & 16.0 & 82.5 \\
\hline $56-65$ years old & 129 & 11.9 & 94.0 & 107 & 10.8 & 93.7 & 236 & 11.4 & 93.9 \\
\hline Less than high school degree & 4 & 0.4 & 0.4 & 5 & 0.5 & 0.5 & 9 & 0.4 & 0.4 \\
\hline $\begin{array}{l}\text { High school graduate (diploma or } \\
\text { equivalent) }\end{array}$ & 88 & 8.1 & 8.5 & 83 & 8.4 & 8.9 & 171 & 8.3 & 8.7 \\
\hline Some college but no degree & 210 & 19.3 & 27.8 & 168 & 17.0 & 26.0 & 378 & 18.2 & 26.9 \\
\hline Associate degree in college (2-year) & 97 & 8.9 & 36.7 & 101 & 10.2 & 36.2 & 198 & 9.6 & 36.5 \\
\hline Bachelor's degree in college & 478 & 44.0 & 80.8 & 402 & 40.8 & 77.0 & 880 & 42.5 & 79.0 \\
\hline $\begin{array}{l}\text { Master's degree or professional } \\
\text { degree (JD, MD, etc) }\end{array}$ & 190 & 17.5 & 98.3 & 203 & 20.6 & 97.6 & 393 & 19.0 & 97.9 \\
\hline$\$ 20,000-\$ 29,999$ & 75 & 6.9 & 17.2 & 96 & 9.8 & 19.1 & 171 & 8.3 & 18.1 \\
\hline$\$ 30,000-\$ 39,999$ & 120 & 11.1 & 28.3 & 88 & 8.9 & 28.0 & 208 & 10.1 & 28.2 \\
\hline$\$ 40,000-\$ 49,999$ & 108 & 10.0 & 38.2 & 104 & 10.6 & 38.6 & 212 & 10.2 & 38.4 \\
\hline$\$ 50,000-\$ 59,999$ & 111 & 10.2 & 48.5 & 103 & 10.5 & 49.1 & 214 & 10.3 & 48.8 \\
\hline$\$ 60,000-\$ 69,999$ & 100 & 9.2 & 57.7 & 85 & 8.6 & 57.7 & 185 & 8.9 & 57.7 \\
\hline$\$ 70,000-\$ 79,999$ & 100 & 9.2 & 66.9 & 75 & 7.6 & 65.3 & 175 & 8.5 & 66.2 \\
\hline$\$ 80,000-\$ 89,999$ & 58 & 5.3 & 72.3 & 68 & 6.9 & 72.3 & 126 & 6.1 & 72.3 \\
\hline$\$ 80,000-\$ 89,999$ & 60 & 5.5 & 77.8 & 71 & 7.2 & 79.5 & 131 & 6.3 & 78.6 \\
\hline$\$ 90,000-\$ 99,999$ & 164 & 15.1 & 92.9 & 128 & 13.0 & 92.5 & 292 & 14.1 & 92.7 \\
\hline$\$ 150,000$ or more & 77 & 7.1 & 100.0 & 74 & 7.5 & 100.0 & 151 & 7.3 & 100.0 \\
\hline \multicolumn{10}{|l|}{ Political orientation } \\
\hline Other & 352 & 32.4 & 32.4 & 292 & 29.6 & 29.6 & 644 & 31.1 & 31.1 \\
\hline Democrat & 441 & 40.6 & 73.0 & 426 & 43.2 & 72.7 & 867 & 41.8 & 72.9 \\
\hline Republican & 294 & 27.0 & 100.0 & 269 & 27.3 & 100.0 & 563 & 27.1 & 100.0 \\
\hline Total & 1087 & 100.0 & & 987 & 100.0 & & 2074 & 100.0 & \\
\hline
\end{tabular}


TA B LE 1 (Continued)

\begin{tabular}{|c|c|c|c|c|c|c|c|c|c|}
\hline & \multicolumn{9}{|c|}{ Graph shown } \\
\hline & No. & $\begin{array}{l}\text { Percentage } \\
\%\end{array}$ & $\begin{array}{l}\text { Cum } \\
\%\end{array}$ & No. & $\begin{array}{l}\text { Percentage } \\
\%\end{array}$ & $\begin{array}{l}\text { Cum } \\
\%\end{array}$ & No. & $\begin{array}{l}\text { Percentage } \\
\%\end{array}$ & $\begin{array}{l}\text { Cum } \\
\%\end{array}$ \\
\hline \multicolumn{10}{|l|}{ Gender } \\
\hline Male & 508 & 46.7 & 100.0 & 449 & 45.5 & 100.0 & 957 & 46.1 & 100.0 \\
\hline \multicolumn{10}{|l|}{ Live in city with $<50 \mathrm{~K}$ people } \\
\hline No & 680 & 62.6 & 62.6 & 601 & 60.9 & 60.9 & 1281 & 61.8 & 61.8 \\
\hline No & 851 & 78.3 & 78.3 & 769 & 77.9 & 77.9 & 1620 & 78.1 & 78.1 \\
\hline Yes & 236 & 21.7 & 100.0 & 218 & 22.1 & 100.0 & 454 & 21.9 & 100.0 \\
\hline
\end{tabular}

Note: Column 1 shows overall distribution, Column 2 shows the distribution for the Linear Group, and Column 3 shows the one for the Log Group.

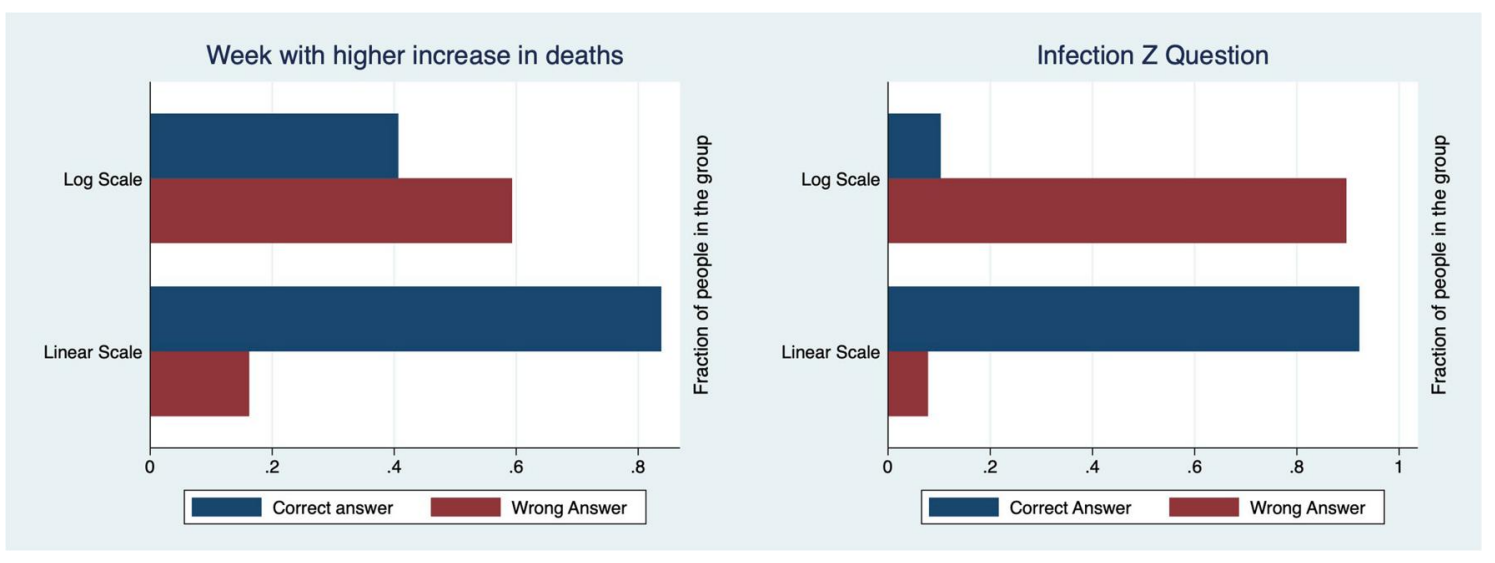

F I G U R E 2 The left panel reports the percentage of correct and incorrect answers provided by the members of the two groups to the understanding question related to COVID-19 real world data. The right panel reports the percentage of correct and incorrect answers provided by the members of the two groups to the understanding question related to Infection $\mathrm{Z}$ hypothetical data

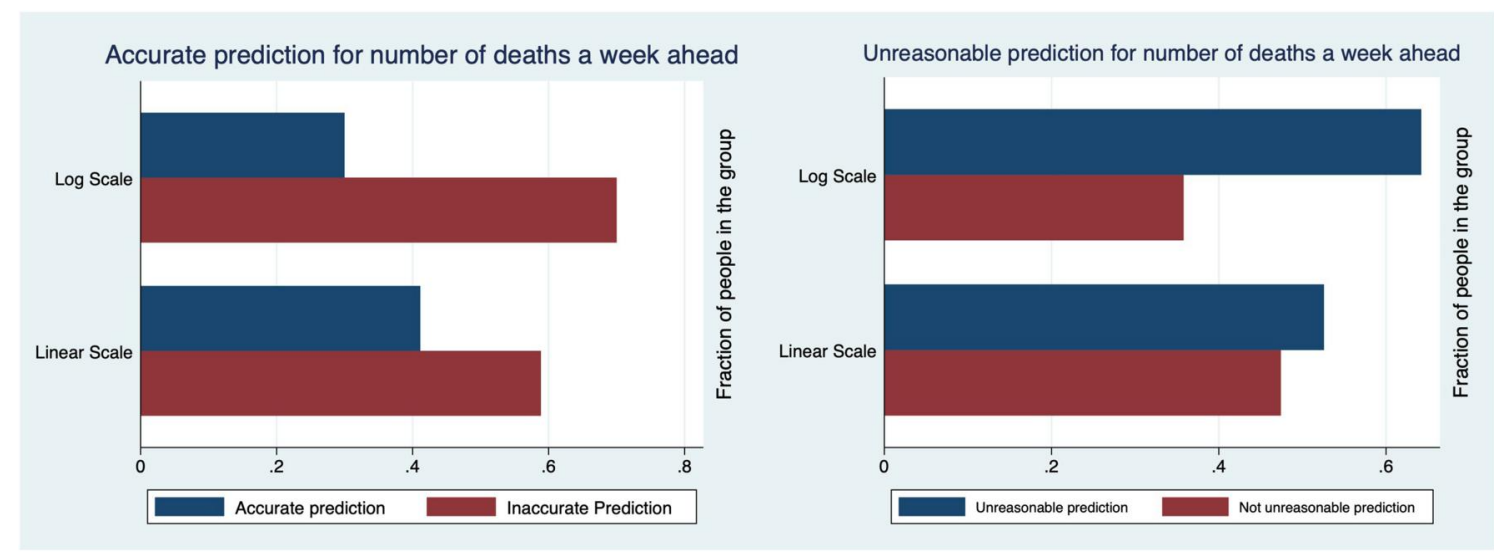

F I G U R E 3 The left panel reports the percentage of accurate and inaccurate (i.e., not accurate) predictions provided by the members of the two groups. The right panel reports the unreasonable and reasonable (i.e., not unreasonable) predictions provided by the members of the two groups 
T A B LE 2 Understanding questions: The coefficients are estimated through a Logit regression

\begin{tabular}{|c|c|c|c|c|}
\hline & \multicolumn{2}{|c|}{ Understanding Q.1: Real data } & \multicolumn{2}{|c|}{ Understanding Q.2: Hypothetical } \\
\hline In Linear Group & $2.021^{* * *}(0.000)$ & $2.054^{* * *}(0.000)$ & $4.634^{* * *}(0.000)$ & $4.819^{* * *}(0.000)$ \\
\hline Confidence in understanding Q.1 & & $0.00886^{* * *}(0.000)$ & & \\
\hline Worry about health crisis & & $-0.0310(0.585)$ & & $-0.0851(0.318)$ \\
\hline Education & & $0.0213(0.619)$ & & $0.152^{* *}(0.021)$ \\
\hline Male & & $-0.147(0.193)$ & & $0.321 *(0.066)$ \\
\hline Age & & $0.00445(0.268)$ & & $0.0154^{* *}(0.012)$ \\
\hline Democrat & & $0.00380(0.977)$ & & $0.0870(0.660)$ \\
\hline Constant & $-0.378^{* * *}(0.000)$ & $-1.375^{* * *}(0.001)$ & $-2.164^{* * *}(0.000)$ & $-6.119^{* * *}(0.000)$ \\
\hline Observations & 2074 & 1830 & 2074 & 1830 \\
\hline
\end{tabular}

Note: $p$-values are reported in parentheses. The standard errors can be found in the Appendix S1. Columns 1 and 2: Right answer to the question on the understanding question on COVID-19 data. Columns 3 and 4: Right answer to question on Infection Z (hypothetical data). All coefficients for the control variables are reported.

${ }^{*} p<0.10,{ }^{* *} p<0.05,{ }^{* * *} p<0.01$.

T A B L E 3 Determinants of making an accurate prediction (Columns 1 and 2) and an unreasonable prediction (Columns 3 and 4)

\begin{tabular}{|c|c|c|c|c|}
\hline & \multicolumn{2}{|c|}{ Accurate prediction } & \multicolumn{2}{|c|}{ Unreasonable prediction } \\
\hline In Linear Group & $0.489^{* * *}(0.000)$ & $0.482^{* * *}(0.000)$ & $-0.481^{* * *}(0.000)$ & $-0.480 * * *(0.000)$ \\
\hline Confidence in prediction & & $-0.00178(0.447)$ & & $0.00188(0.411)$ \\
\hline Worry about health crisis & & $-0.0112(0.830)$ & & $0.0494(0.327)$ \\
\hline Education & & $0.0477(0.221)$ & & $-0.0461(0.224)$ \\
\hline Male & & $-0.0327(0.749)$ & & $-0.0149(0.881)$ \\
\hline Age & & $0.00182(0.616)$ & & $-0.00480(0.175)$ \\
\hline Democrat & & $0.0920(0.437)$ & & $-0.106(0.360)$ \\
\hline Observations & 2074 & 1832 & 2074 & 1832 \\
\hline
\end{tabular}

Note: The coefficients are estimated through Logit regressions. $p$-values are reported in parentheses. The standard errors can be found in the Appendix S1. All coefficients for the control variables are reported.

${ }^{*} p<0.10,{ }^{* * *} p<0.01$.

nonessential business in the first place (Table 5), and would wear government-supplied masks less often (Table 6). These results are statistically significant and robust to a series of different controls and specifications (the regressions presented use Logit and OLS and the results are robust to different sets of controls). The odds ratios show that the magnitude of the effects is non-negligible (Table 7).

These findings are remarkable because the data underlying the graphs is identical. Merely changing the scale can alter public policy preferences and the level of worry, despite the endless flow of COVID-19 related information to which everyone is exposed. 
T A B L E 4 Determinants of worry about health crisis caused by COVID-19

\begin{tabular}{|c|c|c|c|}
\hline & \multicolumn{3}{|c|}{ Worry about health crisis } \\
\hline & (1) & (2) & (3) \\
\hline In Linear Group & $0.141 *(0.081)$ & $0.258 *(0.091)$ & $0.327^{* *}(0.038)$ \\
\hline COVID-19 news checking & & $0.500^{* * *}(0.000)$ & $0.434^{* * *}(0.000)$ \\
\hline Male & & $-0.806^{* * *}(0.000)$ & $-0.654^{* * *}(0.000)$ \\
\hline Understanding Q.1: Real data & & $-0.00425(0.967)$ & $0.00558(0.958)$ \\
\hline Confidence in understanding Q.1 & & $-0.00134(0.706)$ & $-0.00152(0.674)$ \\
\hline Understanding Q.2: Hypothetical & & $-0.137(0.386)$ & $-0.225(0.171)$ \\
\hline Confidence in understanding Q.2 & & $-0.00374(0.302)$ & $-0.00428(0.246)$ \\
\hline Accurate prediction & & $0.156(0.404)$ & $0.218(0.255)$ \\
\hline Unreasonable prediction & & $0.225(0.216)$ & $0.325^{*}(0.084)$ \\
\hline Confidence in prediction & & $0.00622^{* * *}(0.005)$ & $0.00579 * * *(0.009)$ \\
\hline Democrat & & & $0.732 * * *(0.000)$ \\
\hline Republican & & & $-0.282 * *(0.017)$ \\
\hline Worry about economic crisis & & & $0.707^{* * *}(0.000)$ \\
\hline Live in city with $<50 \mathrm{~K}$ people & & & $0.0156(0.880)$ \\
\hline Live in city with $>500 \mathrm{~K}$ people & & & $-0.132(0.280)$ \\
\hline Education & & & $-0.0258(0.473)$ \\
\hline Age & & & $-0.00132(0.694)$ \\
\hline State of residence & & & $0.00777^{* *}(0.030)$ \\
\hline Restrictions in the state & & & $-0.156(0.160)$ \\
\hline Observations & 2074 & 1837 & 1828 \\
\hline
\end{tabular}

Note: The coefficients are estimated through ordered Logit regressions. $p$-values are reported in parentheses. Standard errors can be found in the Appendix S1. All coefficients for the control variables are reported.

${ }^{*} p<0.10,{ }^{* *} p<0.05,{ }^{* * *} p<0.01$.

We cannot know the mechanism leading to these preferences, but we advance the conjecture that the shape of the curves could explain these findings. The flat logarithmic curve can give the impression that we reached a plateau and that, while the present situation is very serious, things are about to get better soon. Thus respondents in the Log Group might be less worried because they feel that the end of the pandemic is near. For the same reason, they could strongly support closing nonessential businesses now, that is, during the peak, but could want to reopen them as soon as the peak is over. Moreover, they might concentrate the use of masks during the peak. As the Log Group thinks we are at the peak, they could also expect a very high number of deaths in the short term, which would also explain their strong support to wear masks and to keep business closed.

Vice versa, the linear curve is constantly growing with no sign of improvement, hence it might give the impression that the crisis will go on for long and will be very serious. Consequently, people in the Linear Group might be more worried and wish to reopen nonessential businesses later. However, they could support closing nonessential businesses relatively less, because they believe that the pandemic will last for a long time, and nonessential businesses cannot remain closed for too long. However, if the decision taken is to close nonessential businesses, they might feel that it would be pointless to do it for a short period of time. They would apply a similar logic to masks. As they believe that the pandemic will last for a long time, they could use them less frequently to ration them.

Regardless of the reasons behind our findings, it is noteworthy that changing the scale can alter policy preferences, intentions to adopt precautionary measures, and level of worry for the health consequences of the pandemic. Given that the scale affects policy preferences and that people have significant problems understanding the logarithmic scale, our 


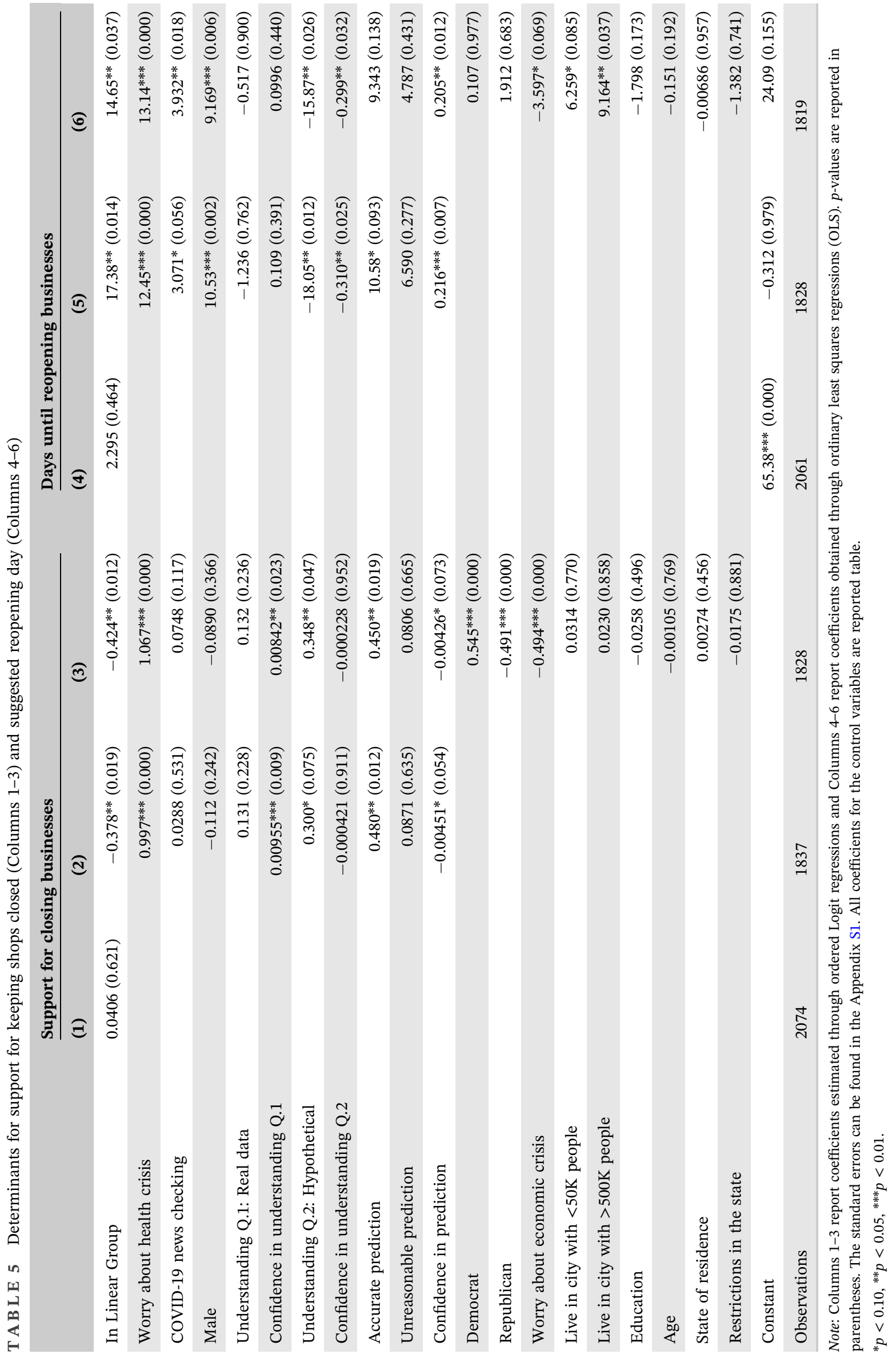




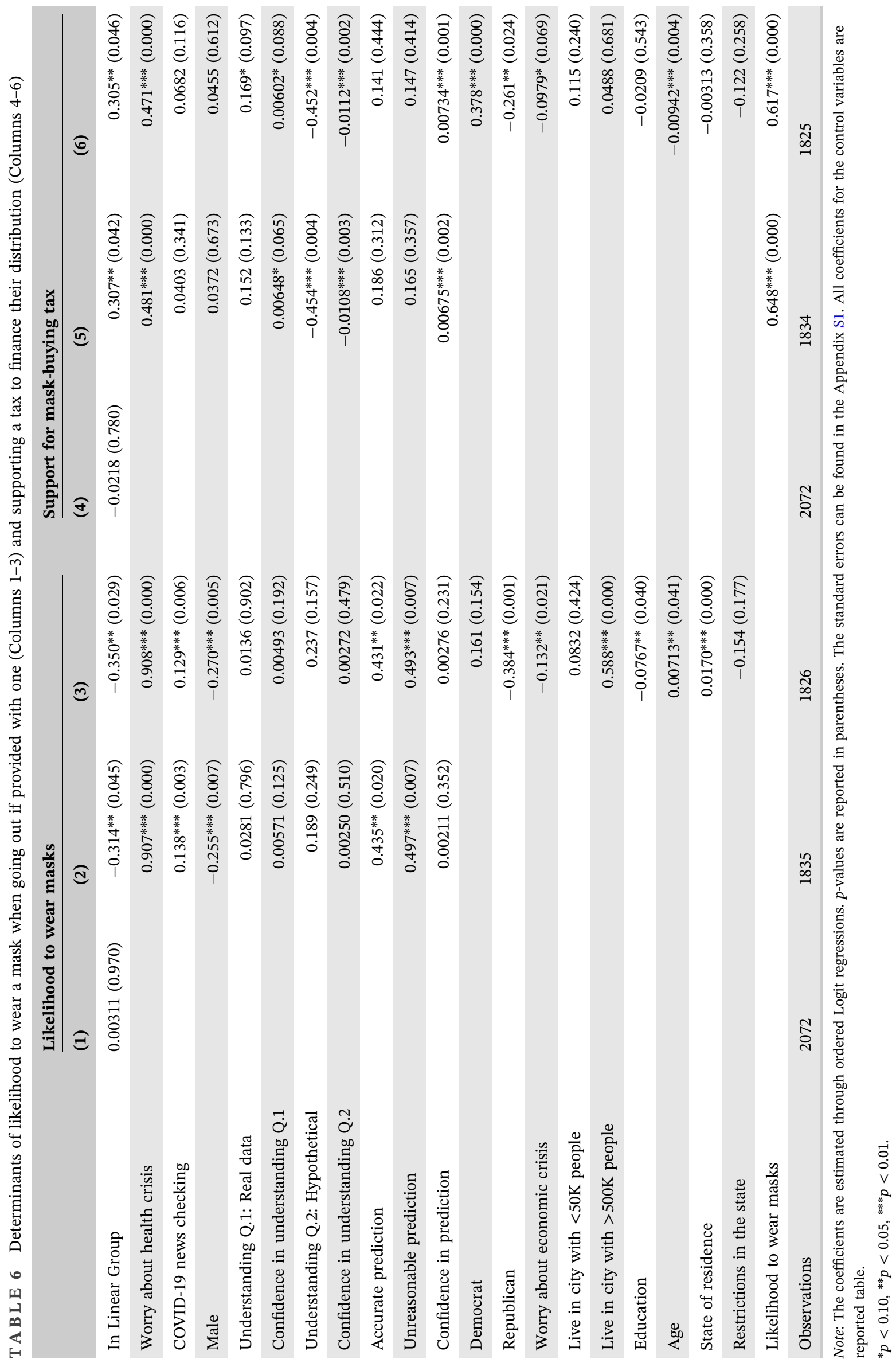




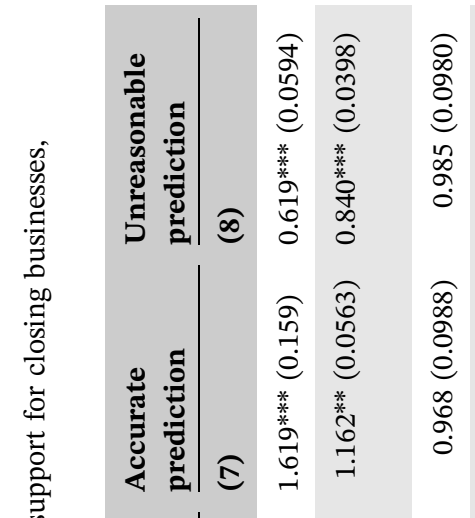

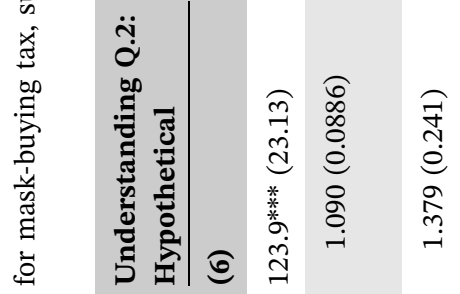

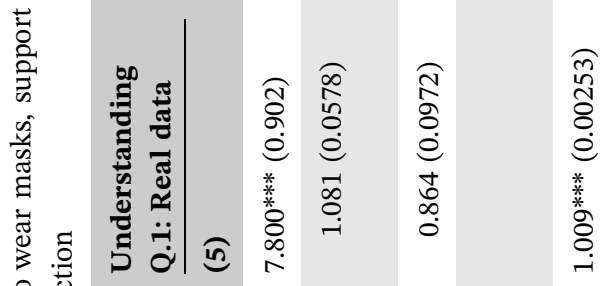

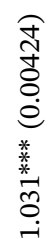

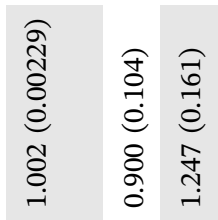

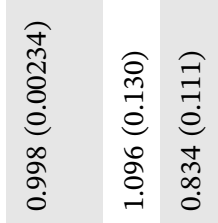

웜

.

:

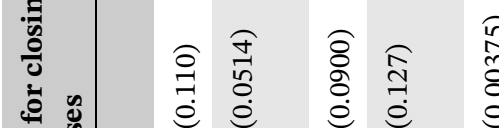

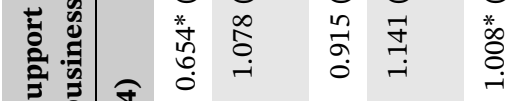

플

穿

芫

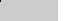

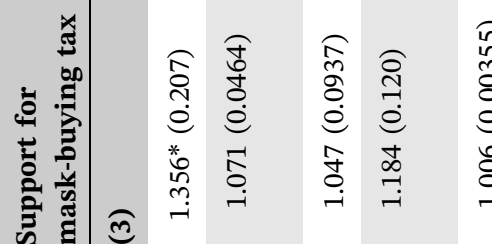

节

苛 त्ष

离

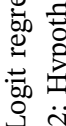

\section{क}

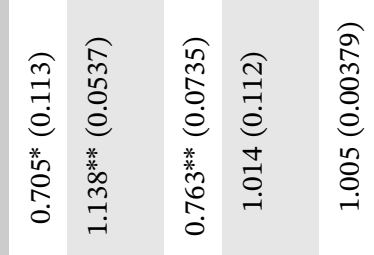

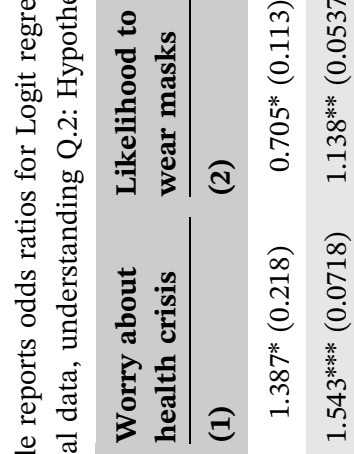

莺

吾

竞量

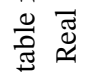

焉

$\sim \stackrel{0, \Xi}{*}$

뙤 듀

1

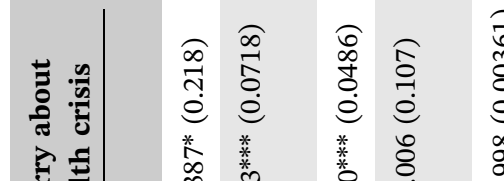

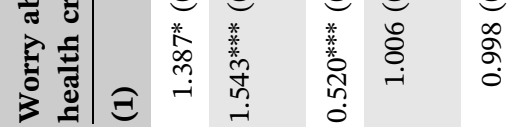

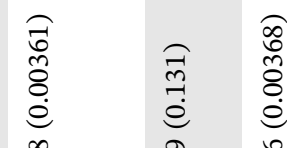

ลे

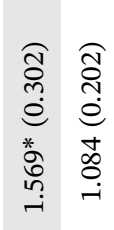

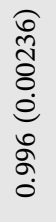

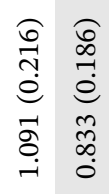

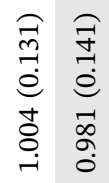

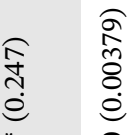

莣

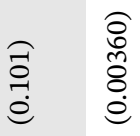

तิ

สิ

$\stackrel{\text { กิ }}{\stackrel{\overbrace{}}{\rightarrow}}$

e e e e

\begin{tabular}{ll}
$*$ & 0 \\
\multirow{2}{*}{} & 0 \\
0 & 0 \\
0 & 0 \\
0 &
\end{tabular}

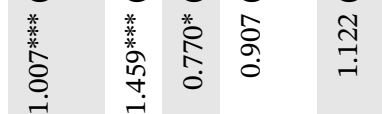

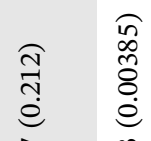

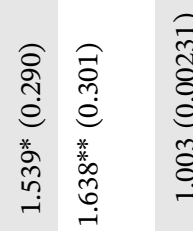

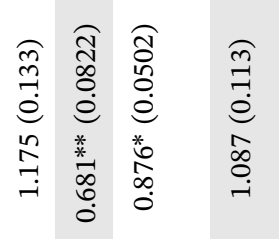

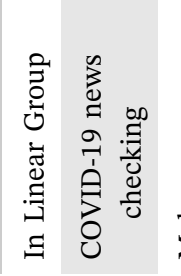

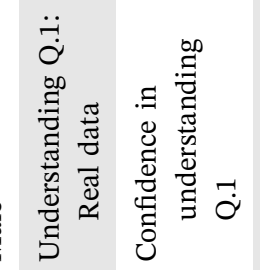

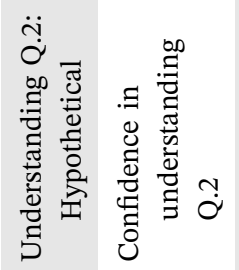

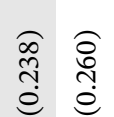

กิ
ธิ
e்

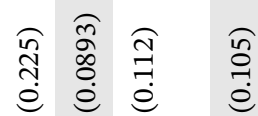

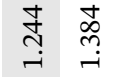

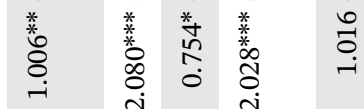

造票

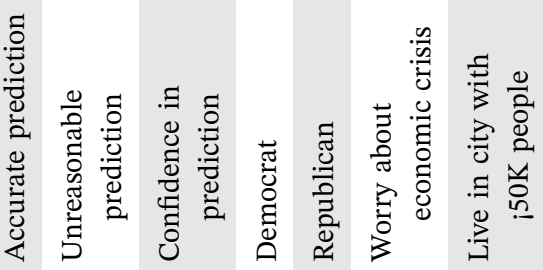



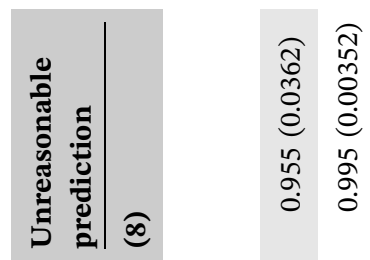

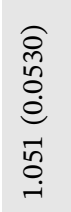

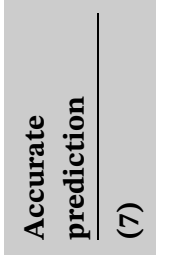

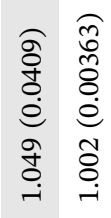

$\stackrel{\infty}{\infty}$

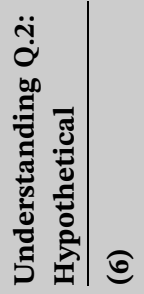

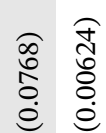

草

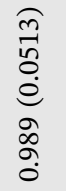

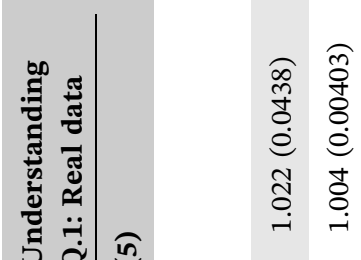

$\widehat{\infty}$
$\infty$
0
0
$\infty$
$\vdots$
0
0

$\stackrel{\infty}{\sim}$

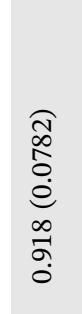

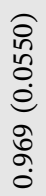

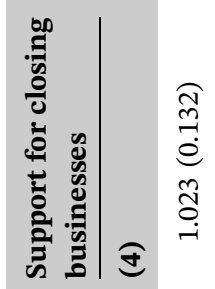

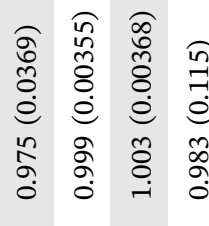

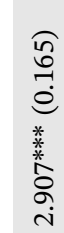

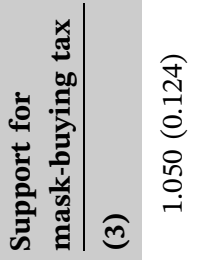

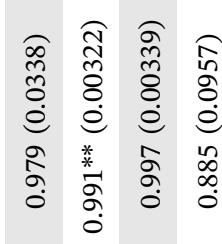

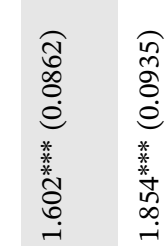

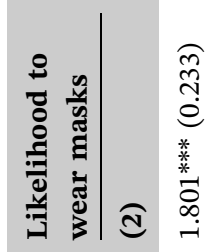

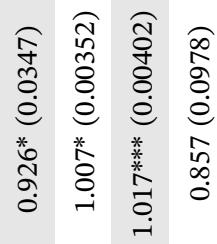

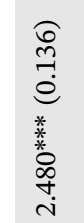

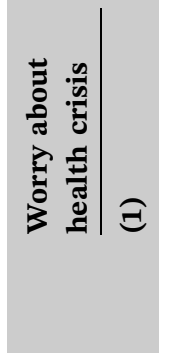

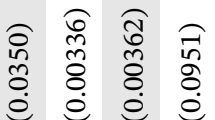

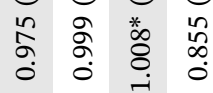

岳

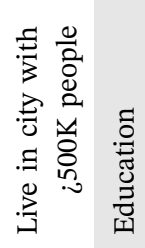

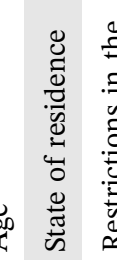

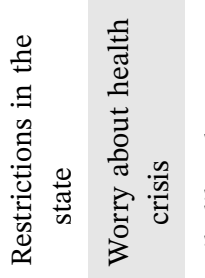

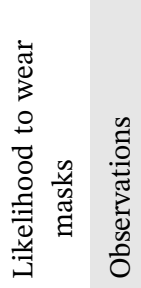

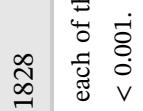

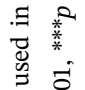

㐫

$\stackrel{\infty}{\infty}$

$\stackrel{\infty}{\infty}$

$\stackrel{\infty}{\rightarrow}$

离

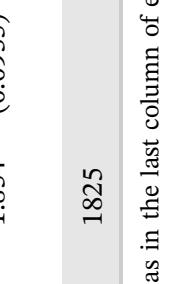

$\stackrel{\infty}{\sim}$

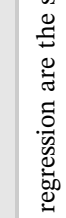


findings suggest that representing data on a linear scale is preferable. Garfin, Silver, and Holman (2020) noted that during a public health crisis, the general public relies on the media to convey accurate and understandable information, so that it can take informed decisions regarding health protective behaviors. Absent information of this kind, people cannot form informed preferences or take informed decisions. Moreover, unclear information conveyed by the media could undermine how much people trust science, which is a key predictor of compliance with COVID-19 guidelines (Brzezinski, Kecht, Van Dijcke, \& Wright Austin, 2020; Phlol \& Musil, 2020).

\section{ACKNOWLEDGMENTS}

The authors wish to thank Ian Ayres, Judith Shapiro, Tom Tyler and Christine Jolls for the valuable feedback provided to us. We also wish to thank two anonymous referees for their insightful comments and suggestions.

\section{ORCID}

Chiara Sotis (10) https://orcid.org/0000-0001-9367-0932

\section{ENDNOTE}

${ }^{1}$ However, their study uses a "catch all" question for pessimism and one on policy preferences. These catch all questions might be unable to capture the nuanced impact of graph scale on policies and attitudes that we observe. For instance, we observe an impact on worry for the health crisis, but not on worry for the economic crisis.

\section{REFERENCES}

Benvenuto, D., Giovanetti, M., Vassallo, L., Angeletti, S., \& Ciccozzi, M. (2020). Application of the arima model on the covid-2019 epidemic dataset. Data in Brief, 29(105340), 1-4.

Brzezinski, A., Kecht, V., Van Dijcke, D., \& Wright Austin, L. (2020). Belief in science influences physical distancing in response to COVID19 lockdown policies. University of Chicago, Becker Friedman Institute for Economics Working Paper 2020-56. https://doi.org/10.2139/ ssrn.3587990

Bursztyn, L., Rao, A., Roth, C., \& Yanagizawa-Drott, D. (2020). Misinformation during a pandemic. University of Chicago, Becker Friedman Institute for Economics Working Paper No. 2020-44. https://dx.doi.org/10.2139/ssrn.3580487

Everett, J., Colombatto, C., Chituc, V., Brady, W. J., \& Crockett, M. (2020). The effectiveness of moral messages on public health behavioral intentions during the covid-19 pandemic. PsyArXiv Preprints. https://doi.org/10.31234/osf.io/9yqs8

Financial Times. (2020). Coronavirus tracked: Has the epidemic peaked near you? Financial Times. Retrieved from https://ig.ft.com/coronavirus-chart/

Garfin, D. R., Silver, R. C., \& Holman, E. A. (2020). The novel coronavirus (COVID-2019) outbreak: Amplification of public health consequences by media exposure. Health Psychology, 5(39), 355-357.

Gladen, B. C. W. J. R. (1983). Brief reports on graphing rate rations. American Journal of Epidemiology, 118(6), 905-908. Retrieved from https://academic.oup.com/aje/article/118/6/905/97120

Heckler, A. F., Mikula, B., \& Rosenblatt, R. (2013). Student accuracy in reading logarithmic plots: The problem and how to fix it. IEEE Frontiers in Education Conference. https://doi.org/10.1109/FIE.2013.6684990

Kosslyn, S. (2006). Graph design for the eye and mind. New York: Oxford University Press.

Levine, M. A., Ahmad, I. E., \& Asa, B. (2010). Relative risk and odds ratio data are still portrayed with inappropriate scales in the medical literature. Journal of Clinical Epidemiology, 63, 1045-1047.

Menge, D., MacPherson, A. C., Bytnerowicz, T. A., Quebbeman, A. W., Schwartz, N. B., Taylor, B. N., \& Wolf, A. A. (2018). Logarithmic scales in ecological data presentation may cause misinterpretation. Nature Ecology \& Evolution, 9(2), 1393-1402.

New York Times. (2020). Coronavirus deaths by U.S. state and country over time: Daily tracker. New York Times. Retrieved from https:// www.nytimes.com/interactive/2020/03/21/upshot/coronavirus-deaths-by-country.html

New York Times. (2020). A different way to chart the spread of coronavirus. New York Times. Retrieved from https:/www.nytimes.com/ 2020/03/20/health/coronavirus-data-logarithm-chart.html

Okan, Y., Galesic, M., \& Garcia-Retamero, R. (2016). How people with low and high graph literacy process health graphs: Evidence from eyetracking. Journal of Behavioral Decision Making, 29(2-3), 271-294.

Phlol, N., \& Musil, B. (2020). Modeling compliance with COVID-19 prevention guidelines: The critical role of trust in science. Psychology, Health \& Medicine, 1-12.

Pidgeon, N., \& Fischhoff, B. (2011). The role of social and decision sciences in communicating uncertain climate risks. Nature Climate Change, 1, 35-41.

Ryan, W., \& Evers, E. (2020). Logarithmic axis graphs distort lay judgment. PsyArXiv Preprints. https://doi.org/10.31234/osf.io/cwt56

Sevi, S., Aviña, M. M., Péloquin-Skulski, G., Heisbourg, E., Vegas, P., Coulombe, M., ... Blais, A. (2020). Logarithmic versus linear visualizations of covid-19 cases do not affect citizens' support for confinement. Canadian Journal of Political Science, 1-6.

The Guardian. (2020). How coronavirus spread across the globe - visualised. The Guardian. Retrieved from https://www.theguardian.com/ world/ng-interactive/2020/apr/09/how-coronavirus-spread-across-the-globe-visualised 
The Washington Post. (2020). What does exponential growth mean in the context of COVID-19? The Washington Post. Retrieved from https://www.washingtonpost.com/weather/2020/03/27/what-does-exponential-growth-mean-context-covid-19/

Van Bavel, J. J., Baicker, K., Boggio, P. S., Capraro, V., Cichocka, A., Cikara, M., ... Willer, R. (2020). Using social and behavioural science to support COVID-19 pandemic response. Nature Human Behaviour, 4, 460-471.

Vox. (2020). Trump's coronavirus death toll estimate exposes his failure. Vox. Retrieved from https://www.vox.com/2020/4/1/21202987/ coronavirus-pandemic-trump-deaths

\section{SUPPORTING INFORMATION}

Additional supporting information may be found online in the Supporting Information section at the end of this article.

How to cite this article: Romano A, Sotis C, Dominioni G, Guidi S. The scale of COVID-19 graphs affects understanding, attitudes, and policy preferences. Health Economics. 2020;1-13. https://doi.org/10.1002/hec.4143 